\title{
Critical Limb Ischemia Treatment Strategies in Diabetics: Present Deeds and Future Challenges
}

\author{
Vlad-Adrian Alexandrescu*1 and Anne Letawe ${ }^{2}$ \\ ${ }^{1}$ Department of Vascular and Thoracic Surgery, Princess Paola Hospital, Belgium \\ ${ }^{2}$ Coordinator of the "Diabetic foot" research database, Marche-en-Famenne, Belgium
}

Submission: November 02, 2015; Published: November 13, 2015

*Corresponding author: Vlad-Adrian Alexandrescu, Department of Vascular and Thoracic Surgery, Princess Paola Hospital, Rue du Vivier 21, 6900 Marche-en-Famenne, Belgium, Tel: 32/84.219076; Fax: 32/84.316613; Email: v.alex@skynet.be

\begin{abstract}
The worldwide number of people suffering from diabetes is anticipated to exceed 350 million by 2030 and the risk for developing critical limb ischemia (CLI) has been documented to reach considerably higher levels in these patients. Contemporary data show that $40 \%$ to $50 \%$ among diabetics may experience an amputation while $20 \%$ to $25 \%$ are prone to die, during the first year of CLI diagnosis. Despite remarkable advances in peripheral arterial revascularization in the last two decades, major amputation rate seems scarcely affected in this group of patients by simultaneous increase of CLI presentations each year.

The present article proposes a succinct review of main revascularization techniques currently reported using surgical, endovascular, or hybrid approaches together with new strategies in enhancing wound-targeted arterial flow reconstruction. Planning to achieve pulsatile flow toward specific foot territories and ischemic ulcers seems to considerably improve the time and quality of tissue healing in diabetic CLI presentation with better limb salvage rates. Novel clinical data equally highlight the importance of parallel macro- and microcirculatory CLI diagnosis inside the multifaceted "diabetic foot syndrome", probably a new paradigm in maximizing postoperative tissue regeneration. In sum, CLI invariably unfolds a multifarious limb-threatening phenomenon particularly pictured in diabetic patients that always have and will request multidisciplinary advises and high-priority local wound and revascularization treatment.
\end{abstract}

Keywords: Critical limb ischemia; Diabetic foot; Ulcer healing; Revascularization; Angiosome

Abbreviations: PAD: Peripheral Arterial Disease; CLI: Critical Limb Ischemia; CTO: Chronic Total Occlusions; DES: Drug-Eluting Stents; EAOD: End-Artery Occlusive Disease; WTR: Wound Targeted Revascularization; ESRD: End Stage Renal Disease

\section{Introduction}

Current data appraise that more than 170 million people suffer from diabetes mellitus nowadays, and their worldwide number is anticipated to reach 366 million by 2030 [1]. The risk for developing peripheral arterial disease (PAD) is considerably increased in diabetic patients, although prone to more frequently experience systemic ischemic events compared to general population [2]. Critical limb ischemia (CLI) embodies the most severe form of PAD (rest pain and ischemic ulcers) $[2,3]$, corresponding to Fontaine stages III/IV and Rutherford categories 4-5 clinical presentations [3]. The term of CLI currently is used for patients that exhibit severe limb ischemic symptoms for more than two weeks [3]. Basic CLI recognition is made by clinical data, anatomical stratification and hemodynamic assessment of flow disturbances in accessible arterial paths [24]. Defining and studying CLI populations prove to be difficult [2-4] due to large heterogeneity and concomitant spread of arterial lesions $[3,4]$, multiple concurrent pathologies $[2,4]$ scarce follow-up data [3] and lack of synchronous macro and microvascular apprehension of gradual hypoxic limb changes
$[2,4,5]$. It is accepted that without precocious recognition and aggressive treatment, CLI inexorably leads to significant morbidity and high rates of major amputation and mortality $[3,4]$. Contemporary clinical experience shows that more than $15 \%$ of diabetic patients will develop a foot ulcer during their lifetime, and 14\%-24\% among them will require amputation [3].

Moreover, during the first year of CLI diagnosis, $40 \%$ to $50 \%$ of diabetics will experience an amputation while $20 \%$ to $25 \%$ among them will die [5]. By applying an optimal treatment as to early increase the oxygenated blood flow in the affected extremity, up to $85 \%$ of amputations can be prevented [3].

\section{Contemporary Developments in Diabetic CLI Therapy}

Despite remarkable progress in CLI treatment in the last twenty years, global major amputation rate in diabetic or renal patients seems only scarcely affected, as reflected in dedicated contemporary literature $[4,6]$.

Outstanding research advances in peripheral arterial 
revascularization, unfortunately, seem to be disparaged by exponentially increasing number CLI suffering subjects each year [2-4]. Modern vascular interventionist yet apprehends to manage manifold therapeutic means as to treat severe infrainguinal atherosclerotic occlusive disease in CLI. Soaring clinical evidence in the last two decades seem to support the endovascular techniques as a useful strategy in CLI revascularization [79]. Providing low invasiveness, high reproducibility and comparable clinical success and limb salvage rates compared to open surgery $[7,9]$ trans-catheter strategies continue to evolve unfolding new low profile and high-performance devices in arterial reconstruction [10]. This assertion seems particularly useful since treating this "high-risk" morbidity and death cohort of patients [1-7].

New antegrade approaches including the "drilling", the "subintimal" and the "parallel wire" techniques owing either the ante-retrograde procedures ("Safari"), the pedal-plantar "loop" technique or spectacular revascularizations throughout femoral-femoral or tibial collaterals were recently described $[9,10]$, as parallel alternatives to overpass arterial chronic total occlusions (CTO).

Nevertheless the "classical" bypass for distal leg reperfusion still detains a major role in CLI diabetic foot tissue healing and limb salvage [11-13]. High-skills distal vein bypasses to the tibial [11], the pedal [13] and up to the plantar or tarsal foot arteries [14] also by targeting remote branches of pedal arteries in some particular cases [12] were successfully documented. Undoubtedly both, surgical and trans-catheter revascularization techniques hold major advantages and inherent drawbacks [15]. Inasmuch endovascular techniques allow minimally invasive and reproducible percutaneous recanalization for one or multiple below-the-knee arteries [7-9], bypass provides a more physiological, high pressure and pulsatile distal flow to the foot [11-14], yielding determinant local effects on collateral shear-stress toward arteriogenesis [4,16] and further tissue cicatrization $[5,6,11,16]$.

Although still heterogeneously structured, novel available clinical observation seems to document equivalent outcomes in limb preservation and survival for surgery versus endoluminal interventions $[4-7,15,16]$. Even though initially considered as competitive [15], the two previously described strategies merge in modern vascular teams rather as complementary approaches to match each specific CLI revascularization $[2,16,17]$.

Even more spectacular advances in diabetic CLI revascularization were testified in the last decade $[4,18]$. New tapered or variable cell-scaffolding bare nitinol stents [19], the drug-eluting stents (DES) [20], or balloon-coated catheters (DEB) [21], associated or not to endoluminal directional or rotational atherectomy [21,22] additionally joining novel "bioresorbable scaffolds" advanced technology [23], are only few of manifold modern peripheral CLI performances in treatment ready to compel ancient endovascular technical barriers [18,21-23].

Parallel to "conventional" arterial reconstruction progresses, new breakthroughs of adjuvant medical therapies were successfully described such as prostaglandin $\mathrm{E}_{1}$ and angiogenetic growth factors manipulations [24] or specific applications for autologous bone marrow-derived cell therapy in CLI patients
[25] and are now available with comparable reported limb preservation results [25].

\section{Particularities in Current Diabetic Foot Revascularization}

As we better apprehend to acknowledge with each passing year the complexity of "Diabetic Foot Syndrome" (DFS), we gain a better understanding on its multifaceted patterns (arteriopathy, neuropathy, sepsis, pressure injuries, cellular and molecular metabolic disturbances, etc.) that unfold myriads of different clinical presentations [26]. This singularity makes even more difficult specific CLI arterial flow appraisal, reconstruction policies and result stratification in whole DFS sources for tissue damages [17,26-28]. Additionally, recent clinical research unveils original macro- and microcirculatory arterial modifications frequently associating CLI neuro-ischemic diabetic foot wounds $[26,27]$. Among these characteristics, regular tibial trunks calcifications $[26,28]$ (corroborating the local neuropathic involvement), $[26,29]$ the "end-artery occlusive disease" (EAOD) concept [29], impaired arterio- and angiogenesis [30], specific foot collateral decay following chronic inflammation and septic thrombosis of small vessels $[16,29,30]$, intrinsic vascular or matrix impaired regeneration [31] and specific compartmental ischemic foot syndromes [32] structure nowadays a more complete and bigger picture of devastating diabetic CLI effects [1,6,26-33]. Contemporary clinicians are also able nowadays to designate alternative strategies [16] for revascularization, in addition to basic technical preparation of interventions $[4,18,28]$.

Beyond already mentioned high-performance techniques and skills for arterial flow reperfusion, modern practitioners equally avail key data about intimate mechanisms of critical ischemic threat and tissue regeneration [30,31]. This knowledge, part of an "integrated medicine care concept" [17], enabled complementary strategies for limb salvage [33-37] and more precise arterial flow re-engineering toward tissue healing $[16,28]$. A new CLI conceptualization rises at present $[4-7,27,33]$, that seems to afford greater serviceableness in patient's selection [26], type of revascularization [4,28] and dedicated postoperative follow-up $[17,26]$.

As a result, novel DFS approaches gathering "hybrid" surgical and endovascular procedures [34], synchronous ante- and retrograde arterial axes accesses [9,35], topographic "wound-directed" arterial reopening [16,36,38-40], deep calf veins arterializations [37] and the "diabetic multidisciplinary team" practice $[17,26,29]$ have been progressively developed and seem to eventually revolutionize previous paradigms of CLI care [4,16,37-39].

One of these redesigned methods is undoubtedly represented by topographic, or intentional "wound targeted" revascularization (WTR) [36,38,39], as the alternate application of the angiosome concept (initially described in 1987 by Taylor in reconstructive plastic surgery) [16,36]. Beyond globally encouraging tissue regeneration and limb preservation results reported for both bypass and endovascular reconstructions [36,38-40], unpredictability still dwells concerning this theory since applied for different CLI etiological patterns $[11,16,36]$. 
Growing contemporary clinical experience yet continues to expand PAD understanding and refine indications for treatment, particularly concerning "low-collateral" CLI presentations [3840] such as the diabetic "neuro-ischemic" or ESRD patients exhibiting foot wounds [16,38-40].

Not surprisingly, alike similar new openings of a flourishing interest in diabetic therapy, the greater available information, the more acrid individual or single-team deliberations and the fiercest requirement for uniform treatment applications [39].

However, parallel to whole progress in CLI understanding perceived at this day and age, new diagnostic and reperfusion challenges are subsequently dawning and may steadily question all spectacular achievements mentioned above [27,39].

\section{The Faith of Diabetic Foot Collaterals: A Core Principle in Modern CLI Treatment}

The consecrated TASC II recommendations [3] toward prompt CLI/DFS revascularization are widely accepted, yet do all these interventions bear similar expectations for tissue recovery? [33] In other words, do we control all macro- and micro-vascular hemodynamic implications at the wound level following CLI revascularization? [33,39] Conversely, do all DFS cases harmonize with TASC II current CLI criteria [3] and hide the analogous amount of ischemic burden? [27,33,39] While several contemporary researchers endeavor to upgrade current CLI statements for each type of arterial pathology [47,26-29], others attempt rather to resize basic ischemic wounds appraisal by new diagnostic methods in a thorough macro and microcirculatory perception [16,29-31,39]. Modern vascular interventionists are now facing a novel challenge concerning specific strategies for revascularization in CLI patients with and without an available foot collateral network [4,11,16,3840]. Available research in diabetic CLI treatment becomes nowadays more and more intimately linked to topographic revascularization strategies [38-40]. Even though that CLI severely distorts expected angiosomal foot vascular model (in pre- and postoperative diagnosis) $[16,40]$, the angiosome scaffolding and appended collateral system still represents a valuable solution for "wound directed" revascularization as to enhance better tissue recovery [36,38].

Today, growing evidence suggests that both macro- and microcirculation evaluation should be routinely considered in each DFS presentation, for better CLI evaluation, as a whole [39].

In this new "regional view" of critical ischemic foot perfusion, although more precise than bare angiographic assessment, not all foot areas may express similar ischemic burden $[16,29,33]$. Even more surprisingly, the ulcer's area could not always represent the lowest perfusion point since severe neuropathy and local skin trauma add complementary hindrance to main DFS threats [26,27,31,33].

Future diagnostic tools focusing on the topographic superficial (the skin level) $[16,40]$ also on deep foot structures (bones, tendons and fascial compartments) [32] can complete this new "regional" and more unitary view of the neuro-ischemic diabetic foot $[33,39]$.

It has been judiciously documented that certain vascular pathologies such as diabetes mellitus and ESRD induce notable infragenicular arterial collateral depletion [29-31]. This momentous loss seems to be proportionate with the type and time of ischemic suffering [5,27-29]. In today's practice, it appears reasonable to adapt the most appropriate technique for reperfusion upon updated CLI definition $[27,33]$ including the macro $[3,41]$ and microvascular information $[42,43]$ in patients with and without available collateral reserve $[16,29,39,40]$.

\section{What the Future Expectations May Be?}

Owning more than seventy years of growing CLI revascularization experience, we know actually that critical ischemic ulcers will probably benefit from any generic revascularization (wound-oriented, or not) $[6,15,18]$ and will elude in some degree threatening ischemic burden since punctually treated $[3,28,33,39]$.

In this context, does new technology [18-24] effectively help diabetic patients to better and quicker heal neuro-ischemic wounds as to regain previous social condition? In other words, does the struggle to reperfuse sometimes "the most challenging" tibial or pedal CTO "wound-oriented" vessel (either by bypass or endovascular means) [38] bestow better outcome regarding amputation-free survival and tissue recovery results? [38,40] If so, the next requisite challenge may be "how" to evaluate successful wound-oriented or topographical revascularization? Are we able today to accurately prove this regional hemodynamic improvement in specific foot territories? $[42,43]$

The vascular community faces nowadays a soaring amount of information about arterial morphological and pathophysiological features in normal subjects also for CLI conditions [2-6,27$30,39]$. New or nearly updated tissue perfusion diagnostic methods are currently proposed almost each year [43] willing to complete "real-time" perioperative vascular information. However, accurate regional flow imaging probably relies not upon single "Mastery" exam assessment (currently overestimated in initiating reports) in "wound oriented" revascularization $[39,43]$. Most complex tissue interactions currently encountered in DFS undoubtedly need a series of complementary exams $[33,42]$ particularly since wound-targeted revascularization is performed [38-40,43-46].

Probably the next generation of diagnostic methods will be able to approach more closely this goal, lot to be desired [43].

It becomes clearer for contemporary clinicians that only complementary macro and micro-circulatory examination (Duplex scan, TCp02, SPP, StO2, Indocyanine green angiography, the PET, SPECT and scintigraphic 99mTc, etc.) [41], associating current angiographic information may afford more comprehensive flow iconography while treating CLI effects $[4,43,44]$.

Beyond available anatomical diagnostic methods, we still need to implement additional time-related or physiological evaluation of revascularization [39]. It becomes of notable importance to equally acknowledge "when" (during what postoperative period) [42-45] flow variables are assessed and compared as pertinentfollow-up results? Recent microcirculatory research describes several physiological phases of blood flow redistribution (immediate, precocious and retarded stages) 
constantly unfolded after successful CLI relief [43]. These predictable transformations include the arteriogenesis, the angiogenesis and the vasculogenesis processes [29,30,43].

The advised rider may remark that only a few publications on wound-directed revascularization available in the contemporary literature, afford synchronous macro and microcirculatory analysis coupled to "regional" and "time-related" flow redistribution evaluation.

In sum, critical limb ischemia invariably unfolds a multifarious limb-threatening phenomenon particularly pictured in diabetic patients that always have and will request multidisciplinary advises $[17,47,48]$ and high-priority local wound and revascularization treatment $[17,37,45,47]$.

\section{Conclusion}

Following growing contemporary clinical experience, CLI definition reaches a greater level of knowledge nowadays, impelling unceasing adaptation to novel macro and microcirculatory evidence.

Current revascularization research still needs homogeneous CLI treatment protocols matching uniform group risk factors, parallel CTO recanalization techniques, and equivalent strategies to improve regional tissue healing.

New concepts and technologies for engineering vascular reconstruction and tissue remodeling marked impressive leaps in contemporary vascular practice. Nevertheless, future evidence for the accuracy of all these new processes toward diminishing CLI destructive effects is still required.

\section{References}

1. Thiruvoipati T, Kielhorn CE, Armstrong EJ (2015) Peripheral artery disease in patients with diabetes: epidemiology, mechanisms, and outcomes. World J Diabetes 6(7): 961-969.

2. Marso SP, Hiatt WR (2006) Peripheral arterial disease in patients with diabetes. J Am Coll Cardiol 47(5): 921-929.

3. Norgreen L, Hiatt WR, Dormandy JA, Nehler MR, Harris KA, et al (2007) Inter-Society Consensus for the management of peripheral arterial disease (TASC II). Eur J Vasc Endovasc Surg 33(Suppl 1): S175.

4. Gulati A, Botnaru I, Garcia LA (2015) Critical limb ischemia and its treatments: a review. J Cardiovasc Surg (Torino) 56(5): 775-785.

5. Elsayed S, Clavijo LC (2015) Critical limb ischemia. Cardiol Clin 33(1): 37-47.

6. Hinchliffe RJ, Andros G, Apelqvist J, Bakker SF, Friederichs S, et al. (2012) A systematic review of the effectiveness of revascularization of the ulcerated foot in patients with diabetes and peripheral disease. Diabetes Metab Res Rev 28(Suppl.1): 179-217.

7. Jens S, Conijn AP, Koelemay MJ, BipatS, Reekers JA (2014) Randomized trials for endovascular treatment of infrainguinal arterial disease: systematic review and meta-analysis (Part 2: Below the knee). Eur J Vasc Endovasc Surg 47(5): 536-544.

8. Alexandrescu VA, Hubermont G, Philips Y, Guillaumie B, Ngongang $\mathrm{Ch}$, et al. (2009) Combined primary subintimal and endoluminal angioplasty for ischaemic inferior-limb ulcers in diabetic patients: 5 -year practice in a multidisciplinary "Diabetic Foot" service. Eur Vasc Endovasc Surg 37(4): 448-456.

9. Park SW, Kim JS, Yun IJ, Hwang JJ, Lee SA, et al. (2013) Clinical outcomes of endovascular treatments for critical limb ischemia with chronic total occlusive lesions limited to below-the-knee arteries. Acta Radiol 54(7): 785-789.

10. Pernès JM, Auguste M, Borie H, Kovarsky S, Bouchareb A, et al. (2015) Infrapopliteal arterial recanalization: A true advance for limb salvage in diabetics. Diagn Interv Imaging 96(5): 423-434.

11. Azuma N, Uchida H, Kokubo T, Koya A, Akasaka N, et al. (2012) Factors influencingwound healing of critical ischaemic footafter bypass surgery: is the angiosome important in selecting bypass target artery? Eur J Vasc Endovasc Surg 43(3): 322-328.

12. Brochado-Neto FC, Cury MV, Bonadiman SS, Matielo MF, Tiossi SR, et al. (2012) Vein bypass to branches of pedal arteries. J Vasc Surg 55(3): 746-752.

13. Good DW, Al Chalabi H, Hameed F, Egan B, Tierney S, et al. (2011) Popliteo-pedal bypass surgery for critical limb ischemia. Ir J Med Sci 180(4): 829-835.

14. Hughes K, Domenig CM, Hamdan AD, Schermerhorn M, Aulivola B, et al. (2004) Bypass to plantar and tarsal arteries: an acceptable approach to limb salvage. J Vasc Surg 40(6): 1149-1157.

15. Abu Dabrh AM, Steffen MW, Asi N, Undavalli C, Wang Z, et al. (2015) Bypass surgery versus endovascular interventions in severe or critical limb ischemia. J Vasc Surg S0741-5214(15)01628-6.

16. Alexandrescu VA (2012) The angiosome concept: anatomical background and physiopathological landmarks in CLI (Chapter 1). In: Angiosomes applications in Critical Limb Ischemia: in search for relevance. Minerva Medica Publ pp.1-30,71-88.

17. Alexandrescu VA, Hubermont G, Coessens V, Philips Y, Guillaumie B, et al. (2009) Why a multidisciplinary team may represent a key factor for lowering the inferior limb loss rate in diabetic neuro-ischaemic wounds : application in a departmental institution. Acta Chir Belg 109(6): 694-700.

18. Gulati A, Botnaru I, Garcia LA (2015) Critical limb ischemia and its treatments: a review. J Cardiovasc Surg (Torino) 56(5): 775-785.

19. Taneja M, Tay KH, Dewan A, Sebastian MG, Pasupathy S, et al. (2010) Bare nitinol stent enabled recanalization of long-segment, chronic total occlusion of superficial femoral and adjacent proximal popliteal artery in diabetic patients presenting with critical limb ischemia. Cardiovasc Revasc Med 11(4): 232-235.

20. Spiliopoulos S, Theodosiadou V, Katsanos K, Kitrou P, Kagadis GC, et al. (2015) Long-term clinical outcomes of infrapopliteal drug-eluting stent placement for critical limb ischemia in diabetic patients. J Vasc Interv Radiol 26(10): 1423-1430.

21. Baerlocher MO, Kennedy SA, Rajebi MR, Baerlocher FJ, Misra S, et al. (2015) Meta-analysis of drug-eluting balloon angioplasty and drugeluting stent placement for infrainguinal peripheral arterial disease. J Vasc Interv Radiol 26(4): 459-473.

22. Cioppa A, Stabile E, Popusoi G, Salemme L, Cota L, et al. (2012) Combined treatment of heavy calcified femoro-popliteal lesions using directional atherectomy and a paclitaxel coated balloon: Oneyear single centre clinical results. Cardiovasc Revasc Med 13(4): 219223.

23.Zeller T, Rastan A, Macharzina R, Beschorner U, Noory E (2015) Novel approaches to the management of advanced peripheral artery disease: perspectives on drug-coated balloons, drug-eluting stents, and bioresorbable scaffolds. Curr Cardiol Rep 17(9): 624-627.

24. Abu Dabrh AM, Steffen MW, Asi N, Undavalli C, Wang Z, et al. (2015) Nonrevascularization-based treatments in patients with severe or critical limb ischemia. J Vasc Surg 62(5): 1330-1339.

25. Teraa M, Sprengers RW, van der Graaf Y, Peters CE, Moll FL, et al. (2013) Autologous bone marrow-derived cell therapy in patients with critical limb ischemia: a meta-analysis of randomized controlled 
clinical trials. Ann Surg 258(6): 922-929.

26. Lepantalo M, Apelquist J, Setacci C, Ricco JB, de Donato G, et al. (2011) Chapter V: Diabetic foot. Eur J Vasc Endovasc Surg 42(Suppl 2): S60-S74.

27. Jörneskog G (2012) Why critical limb ischemia criteria are not applicable to diabetic foot and what the consequences are. J Scan Surg 101(2): 114-118.

28. Mills JL Sr (2015) Lower limb ischemia in patients with diabetic foot ulcers and gangrene: recognition, anatomic patterns and revascularization strategies. Diabetes Metab Res Rev 11: doi 10.1002/dmrr.2753.

29. O'Neal LW (2008) Surgical pathology of the foot and clinicopathologic correlations. In: Levin and O'Neal's The Diabetic Foot. Philadelphia: Mos- by Elsevier 18: 367-401.

30. Waltenberg J (2001) Impaired collateral vessel development in diabetes: potential cellular mechanisms and therapeutic implications. Cardiovasc Res 49(3): 554-560.

31. Dangwal S, Stratmann B, Bang C, Lorenzen JM, Kumarswamy R, et al. (2015) Impairment of wound healing in patients with type 2 diabetes mellitus influences circulating microRNA patterns via inflammatory Cytokines. Arterioscler Thromb Vasc Biol 35(6): 1480-1488.

32. Alexandrescu VA, Van Espen D (2014) Threatening inferior limb ischemia : when to consider fasciotomy and what principles to apply? ISRN Vasc Med 21: 1-9.

33. Vallabhaneni R, Kalbaugh CA, Kouri A, Farber MA, Marston WA (2015) Current accepted hemodynamic criteria for critical limb ischemia do not accurately stratify patients at high risk for limb loss. J Vasc Surg S0741-5214(15)01748-6.

34. Dosluoglu HH, Lall P, Cherr GS, Harris LM, Dryjski ML (2010) Role of simple and complex hybrid revascularization procedures for symptomatic lower extremity occlusive disease. J Vasc Surg 51(6): 1425-1435

35. Bazan HA, Le L, Donovan M, Sidhom T, Smith TA, et al. (2014) Retrograde pedal access for patients with critical limb ischemia. J Vasc Surg 60(2): 375-381.

36. Biancari F, Juvonen T (2014) Angiosome-targeted lower limb revascularization for ischemic foot wounds: systematic review and meta-analysis. Eur J Vasc Endovasc Surg 47(5): 517-522.

37. Alexandrescu VA (2012) Is limb loss always inevitable for critical neuro-ischemic foot wounds in diabetic patients with end stage renal disease and unfit for vascular reconstructions? In: Sahay M, (Ed.), Diseases of Renal Parenchyma. Rijeka, Croatia: InTech Open Science
228-246.

38. Spillerova K, Biancari F, Leppäniemi A, Albäck A, Söderström M, et al. (2014) Differential impact of bypass surgery and angioplasty on angiosome-targeted infrapopliteal revascularization. Eur J Vasc Endovasc Surg 49(4): 412-419.

39. Alexandrescu VA (2014) Commentary: Myths and proofs of angiosome applications in CLI: where do we stand? J Endovasc Ther 21(5): 616-624

40. Iida O, Takahara M, Soga Y, Yamauchi Y, Hirano K, et al. (2014) Impact of angiosome-oriented revascularization on clinical outcomes in critical limb ischemia patients without concurrent wound infection and diabetes. J Endovasc Ther 21(5): 607-615.

41. Jaff MR, White CJ, Hiatt WR, Fowkes GR, Dormandy J, et al. (2015) An update on methods for revascularization and expansion of the TASC lesion classification to include below-the-knee arteries: a supplement to the Inter-Society Consensus for the management of peripheral arterial disease (TASC II). J Endovasc Ther 22(5): 663-677.

42. Okamoto S, Iida O, Nakamura M, Yamauchi Y, Fukunaga M, et al. (2015) Postprocedural skin perfusion pressure correlates with clinical outcomes 1 year after endovascular therapy for patients with critical limb ischemia. Angiology 66(9): 862-866.

43. Alexandrescu VA, London V (2015) Angiosomes: the cutaneous and arterial evaluation in CLI patients. (Chapter 5), In: Mustapha JA (Ed.), Critical Limb Ischemia: CLI diagnosis and interventions. HMP, Chicago, 71-88.

44. Chin JA, Sumpio BE (2014) New advances in limb salvage. Surg Technol Int 25: 212-216.

45. Bunte MC, Shishehbor MH (2013) Treatment of infrapopliteal critical limb ischemia in 2013: the wound perfusion approach. Curr Cardiol Rep 15(6): 363.

46. Huang TY, Huang TS, Wang YC, Huang PF, Yu HC, et al. (2015) Direct revascularization with the angiosome concept for lower limb ischemia : a systematic review and meta-analysis. Medicine (Baltimore) 94(34): e1427.

47. Lepantalo M (2012) The path from art to evidence in treating critical limb ischemia : reflections on 35 years' experience. Scand J Surg 101(2): 78-85.

48. Brooke BS, Kraiss LW, Stone DH, Nolan B, De Martino RR, et al (2014) Improving outcomes for diabetic patients undergoing revascularization for critical limb ischemia: does the quality of outpatient diabetic care matter? Ann Vasc Surg 28(7): 1719-1728. 